\title{
Photoinduced CO-Reduction in Aqueous Suspension of $\mathrm{n}-\mathrm{TiO}_{2}$
}

\author{
Hyoung-Ryun Park, Guozheng Li*, and Nikola Getoff \\ Institut für Theoretische Chemie und Strahlenchemie der Universität \\ and Ludwig-Boltzmann-Institut für Strahlenchemie, Wien, Austria
}

Z. Naturforsch. 43a, 1126-1130 (1988); received October 19, 1988

$\mathrm{TiO}_{2}$-suspension as well as $\mathrm{TiO}_{2}$-colloide in aqueous solutions are acting as catalyst for transforming $\mathrm{CO}$ into formaldehyde under illumination with uv-light. The yield of formaldehyde was studied as a function of $\mathrm{pH}$ (range: $1-7$ ) and of the $\mathrm{n}-\mathrm{TiO}_{2}$ content in the suspension at $\mathrm{pH} 2$. Probable reaction mechanisms are presented.

\section{Introduction}

The photoinduced transformation of aqueous carbon monoxide into formaldehyde, glyoxal, carboxylic acids and small amounts of glycol using vacuum-uvlight $(\lambda=185 \mathrm{~nm})$ was reported very recently [1] It was established that the quantum yield of these products strongly depends on the $\mathrm{pH}$. Further, the photolysis of aqueous formaldehyde in the presence of $\mathrm{CO}$ essentially diminishes and in addition the formation of glyoxal, formic and oxalic acids is observed [2]. The initial processes are based on the $\mathrm{H}$ and $\mathrm{OH}$ radicals resulting from the water photolysis at $185 \mathrm{~nm}$. On the other hand it has been shown that water decomposition to $\mathrm{H}_{2}$ and $\mathrm{O}_{2}$ occurs by illuminating $\mathrm{n}-\mathrm{TiO}_{2}$ particles in form of acidified aqueous suspension with light of $\lambda \geqq 300 \mathrm{~nm}[3,4]$. Using appropriate scavengers (e.g. ferri-ions, alcohol etc.) it was found that on the surface of $\mathrm{n}-\mathrm{TiO}_{2} \mathrm{H}$ and $\mathrm{OH}$ species are formed as primary species of water splitting [5]. Similar processes can also take place on the surface of platinized $\mathrm{TiO}_{2}$-particles or colloids $[6,7$ and ref. therein]. Using $\mathrm{p}-\mathrm{Si}$ plate electrodes and powders, Yamamura et al. [8] succeeded to reduce $\mathrm{CO}$ to formaldehyde. The p-Si electrodes were coated with either porphyrins or metals in order to avoid corrosion. By illuminating with a $500 \mathrm{~W}$ Xenon lamp $\left(150 \mathrm{~mW} / \mathrm{cm}^{2}\right)$ during $4-8 \mathrm{hr}$ they obtained in acid solutions aldehyde yields of $0.39-0.86 \times 10^{-6} \mathrm{M}$. In the case of $\mathrm{p}$-Si suspensions (acidified or containing ethanol) the

\footnotetext{
* Department of Chemistry, Shandong University, 27 ShanDa-Nan-Road, Jinan, Shandong, PR China.

Reprint requests to Prof. Dr. Nikola Getoff, Institut für Theoretische Chemie und Strahlenchemie, Ludwig-Boltzmann-Institut, Universität Wien, Währingerstraße 38, A-1090 Wien, Österreich.
}

yields were somewhat lower, namely $0.21-0.32 \times$ $10^{-6} \mathrm{M}$ HCHO.

Based on these observations it appeared very promising to reduce $\mathrm{CO}$ in aqueous solution in the presence of finely pulverized $\mathrm{n}-\mathrm{TiO}_{2}$ under the influence of light of $\lambda \geqq 300 \mathrm{~nm}$. The problem is of special interest for an eventual utilization of $\mathrm{CO}$ produced in large amounts by combustion of fossil fuels.

\section{Experimental}

\section{Preparation of Solutions}

At least triply distilled water was used for the preparation of the solutions, which were saturated with high purity $\mathrm{CO}\left(1 \times 10^{-3} \mathrm{M} \mathrm{CO}\right.$; Messer Griesheim, Austria) at $20^{\circ} \mathrm{C}$. As a catalyst two types of $\mathrm{TiO}_{2}$ were used: colloide and fine powders. The $\mathrm{TiO}_{2}$-colloids were prepared according to the method by Moser and Grätzel [9] by hydrolysis of $\mathrm{TiCl}_{4}$. The obtained colloide possesses an absorption maximum at $\lambda=$ $415 \mathrm{~nm}$ and $\varepsilon=640 \mathrm{~cm}^{3} \mathrm{M}^{-1} \mathrm{~cm}^{-1}[10] . \mathrm{TiO}_{2}$ powder (anatase, Fluka) was first heated for $60 \mathrm{~min}$ at $1150{ }^{\circ} \mathrm{C}$ in the presence of oxygen and then treated in $\mathrm{H}_{2}$ atmosphere at $700{ }^{\circ} \mathrm{C}$ for $90 \mathrm{~min}$. Due to this operations, an $\mathrm{n}-\mathrm{TiO}_{2}$ powder rutile structure is obtained. It was granulated and sieved. Only $\mathrm{n}-\mathrm{TiO}_{2}$ with a grain size $\leqq 0.06 \mathrm{~mm}$ was used as suspension in aqueous solution. For adjustment of the pH, p.a. $\mathrm{HClO}_{4}$ and $\mathrm{NaOH}$ (Merck) were used.

\section{Light Sources and Actinometry}

A low pressure Hg-lamp (Osram, HNS $10 \mathrm{~W}$ ) with incorporated filter for absorping vuv-line $(185 \mathrm{~nm})$ provided a monochromatic uv-light with $\lambda=254 \mathrm{~nm}$. 
The actinometry was carried out using a monochloric acetic acid-actinometer [11]. The intensity of the lamp, $I_{0}=5.0 \times 10^{17} \mathrm{hv} \cdot \mathrm{ml}^{-1} \mathrm{~min}^{-1}$, was controlled periodically and was found to be constant. As a second light source served a medium pressure $\mathrm{Hg}$ lamp (Philips, HPK $125 \mathrm{~W}$ ), which emits a number of lines $(312.6 / 313.4,334,365.2 / 365.6 / 366.5,405.8,407.8$, $435.4,545.8,576$ and $578 \mathrm{~nm})$. The light with $\lambda<300$ $\mathrm{nm}$ was removed by a "Duran 60 " glass filter.

\section{Chemical Analysis}

Formaldehyde was found to be the main product of the CO-reduction on the $\mathrm{TiO}_{2}$ surface. For its determination in the presence of acetyldehyde, glyoxal, glyoxyl acid and formic acid the method by Hantz [12] was found to be the most suitable one. As reagent was used a solution containing $25 \mathrm{~g}$ ammonium acetate, $3 \mathrm{ml} \mathrm{100 \%}$ acetic acid and $0.2 \mathrm{ml}$ acetylacetone, filled up to $100 \mathrm{ml}$ with triply distilled water. The solution is stable for more than one month when kept in a refrigerator. The analysis of formaldehyde was performed by adding $2 \mathrm{ml}$ reagent to $5 \mathrm{ml}$ sample and filling up to $10 \mathrm{ml}$ with triply distilled water. Before analysis $\mathrm{TiO}_{2}$ was removed from the irradiated solution by filtration. After keeping the mixture for $50 \mathrm{~min}$ at $37 \pm 1{ }^{\circ} \mathrm{C}$, and then $20 \mathrm{~min}$ at room temperature, the optical density was measured against a reference sample at $\lambda=412 \mathrm{~nm}\left(\varepsilon_{412}=8000 \mathrm{~cm}^{3} \mathrm{M}^{-1} \mathrm{~cm}^{-1}\right)$ [11].

\section{Results and Discussion}

\section{Irradiation with $u v$-Light $\lambda=254 \mathrm{~nm}$}

For this series of experiments n- $\mathrm{TiO}_{2}$ powder (rutile, grain size $\leqq 0.06 \mathrm{~mm}$ ) was used as an aqueous suspension $(0.5$ to $5 \mathrm{mg} \mathrm{TiO} / \mathrm{ml})$. The $\mathrm{CO}$-saturated solutions $\left(1 \times 10^{-3} \mathrm{M} \mathrm{CO}\right)$ were irradiated at $20 \pm 1{ }^{\circ} \mathrm{C}$ (thermostat) under stirring in order to keep the suspension homogeneous. Formaldehyde was found as a main product, in addition to very small amounts of glyoxal and carboxylic acids. The HCHO-yield was first studied as a function of the uv-dose at $\mathrm{pH} 2$ and 7. The obtained data are presented in Figure 1. The initial quantum yields $\left(Q_{\mathrm{i}}\right)$ were calculated from the tangent of curves $\mathrm{A}$ and $\mathrm{B}$ plotted through the zero of the coordinate system. Obviously, the $Q_{\mathrm{i}}(\mathrm{HCHO})$ value is essentially higher in acid than in neutral media.

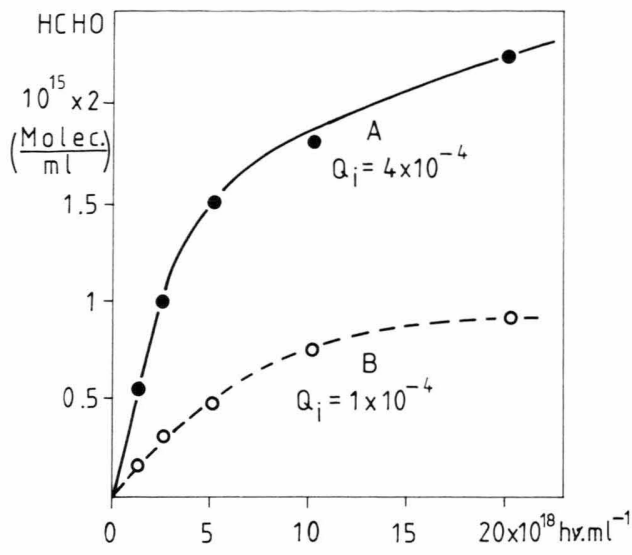

Fig. 1. Formation of formaldehyde from $1 \times 10^{-3} \mathrm{M} \mathrm{CO}$ in an aqueous suspension of $1 \mathrm{mg} \mathrm{TiO}_{2} / \mathrm{ml}$ as a function of uv-dose using uv-light with $\lambda=254 \mathrm{~nm}$ at $\mathrm{pH} 2$ (A) and pH 7 (B).

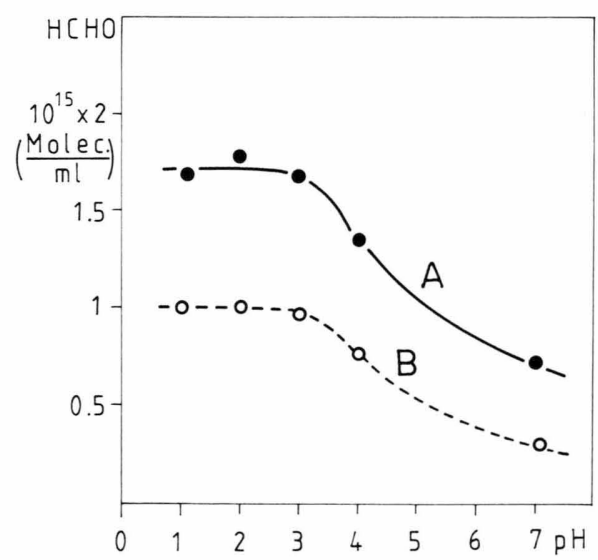

Fig. 2. pH-dependence of formaldehyde formation from $1 \times 10^{-3} \mathrm{M} \mathrm{CO}$ in an aqueous suspension of $1 \mathrm{mg} \mathrm{n}-\mathrm{TiO}_{2} / \mathrm{ml}$ using uv-light with $\lambda=254 \mathrm{~nm}$. Applied dose: $1 \times 10^{19} h v / \mathrm{ml}$ (A) and $2.51 \times 10^{18} h v / \mathrm{ml}$ (B). $\left(I_{0}^{254}=5 \times 10^{17} h v / \mathrm{ml}^{-1} \mathrm{~min}^{-1}\right.$.)

This result initiated the study of the $\mathrm{pH}$-dependence of the HCHO-formation under otherwise the same conditions. Figure 2 shows the rather strong decrease of the product yield in acid solutions from $Q_{\mathrm{A}}=$ $1.7 \times 10^{-4}$ at $\mathrm{pH} 1$ to 3 to $Q_{\mathrm{A}}=0.7 \times 10^{-4}$ at $\mathrm{pH} 7$. The corresponding $Q$-values for curve B are $1 \times 10^{-4}$ and $0.3 \times 10^{-4}$, respectively.

In addition to this, an interesting aspect represents the formation of $\mathrm{HCHO}$ as a function of the $\mathrm{TiO}_{2}$ content in the CO-saturated suspension. This correlation is pictured in Fig. 3 for two uv-doses at $\mathrm{pH}$ 2. In both cases the aldehyde formation is linear with the 


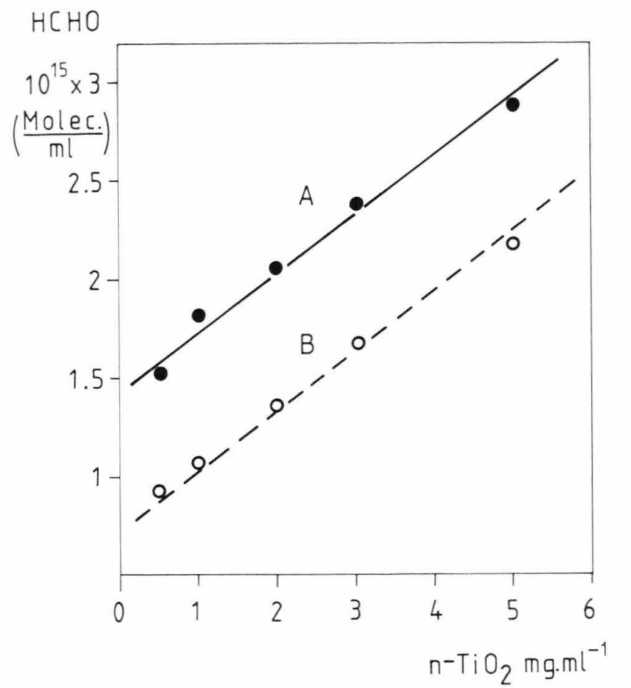

Fig. 3. Formaldehyde formation from $1 \times 10^{-3} \mathrm{M} \mathrm{CO}$ vs. $\mathrm{n}$ - $\mathrm{TiO}_{2}$-content in the suspension $(\mathrm{pH} 2)$ using uv-light with $\lambda=254 \mathrm{~nm}$ at an uv-dose of $1 \times 10^{19} h v / \mathrm{ml}$ (A) and $2.51 \times 10^{18} h v / \mathrm{ml}(\mathrm{B})$ respectively.

concentration of $\mathrm{n}-\mathrm{TiO}_{2}$ in the solution and in unison with the applied dose.

\section{Irradiation with Medium Pressure Hg-Lamp (HPK $125 \mathrm{~W}$ )}

As mentioned above, this lamp emits light with various wavelengths, most of which are practically absorbed by the $\mathrm{n}-\mathrm{TiO}_{2}$-colloid or fine particles, respectively. Both, colloids and particles are able to reduce $\mathrm{CO}$ under the present conditions. Further, it was established that with rising the $\mathrm{pH}$ of the solutions the formaldehyde yield decreases rapidly. In Fig. 4 some results from $\mathrm{CO} / \mathrm{n}-\mathrm{TiO}_{2}$ particles system at $\mathrm{pH} 2$ are presented. Curve A illustrates the fact that above a certain light dose ( $>40$ min irradiation time) the aldehyde yield remains constant. This indicates the occurrence of back reactions on the catalyst surface. The strong $\mathrm{pH}$-dependence of the aldehyde yield is demonstrated by curve B. It might be mentioned that in alkaline solutions $(\mathrm{pH}>9)$ no formaldehyde was detectable.

\section{Discussion}

By immerging of an n-type semiconductor in an aqueous electrolyte a band-bending takes place and

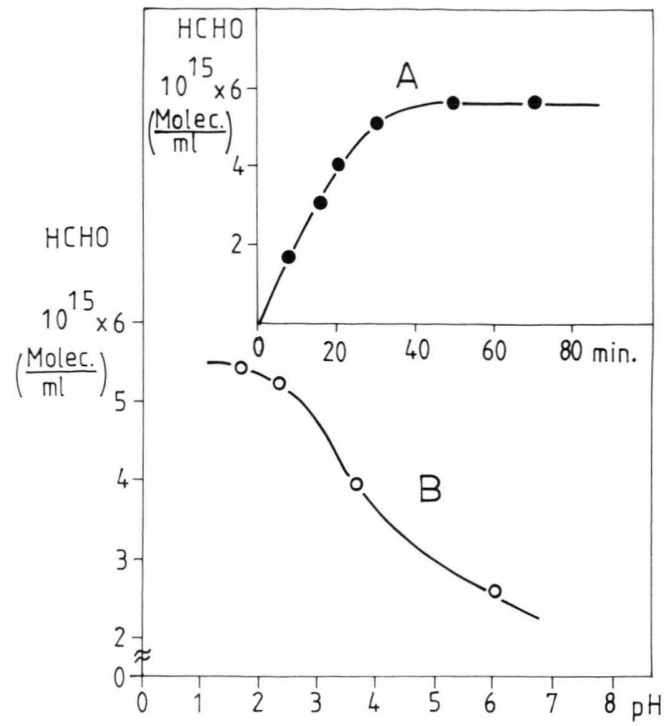

Fig. 4. (A) Formaldehyde formation as a function of irradiation time (HPK, $125 \mathrm{~W}$-lamp) using $\mathrm{CO}$-saturated aqueous solution $(\mathrm{pH} 2)$ in the presence of $1 \mathrm{mg} \mathrm{n}-\mathrm{TiO}_{2} / \mathrm{ml}$. (B) $\mathrm{pH}$ Dependence of the aldehyde yield obtained under the same experimental conditions (irrad. time: $30 \mathrm{~min}$ ).

under illumination electrons are rised from the valence-band $\left(E_{\mathrm{V}}\right)$ to the conduction band $\left(E_{\mathrm{C}}\right)[13$, 14]. The energy difference between both levels (band gap, $E_{\mathrm{G}}$ in $\mathrm{eV}$ ) is a characteristic value for each kind of semiconductor. In the case of $\mathrm{n}-\mathrm{TiO}_{2}, E_{\mathrm{G}}=3.1 \mathrm{eV}$, which corresponds to a light with $\lambda \cong 400 \mathrm{~nm}$. The applied low pressure $\mathrm{Hg}$-lamp emitts $\lambda=254 \mathrm{~nm}$, which corresponds to $4.8 \mathrm{eV} / h v$, whereas the medium pressure Hg-lamp provides energies from $2.13 \mathrm{eV} /$ quant $(\lambda=578 \mathrm{~nm})$ to $3.9 \mathrm{eV} /$ quant $(312.6 \mathrm{~nm})$. Hence, it is obvious that when using the second lamp the light with $\lambda>430 \mathrm{~nm}$ is practically not utilized.

By illumination of $n-\mathrm{TiO}_{2}$ aqueous suspension the following reactions take place:

$\mathrm{TiO}_{2} \stackrel{h v}{\rightarrow} *$ TiO $\mathrm{TiO}_{2} \longrightarrow\left(\mathrm{e}^{-} \cdot \mathrm{TiO}_{2}^{+}\right) \rightarrow \mathrm{e}^{-}+\mathrm{TiO}_{2}^{+}$.

The system $\left(\mathrm{e}^{-} \cdot \mathrm{TiO}_{2}^{+}\right)$is identical with $\left(\mathrm{e}^{-} \cdot \mathrm{p}^{+}\right)$, where $\mathrm{p}^{+}$(positive holes) corresponds to $\mathrm{TiO}_{2}^{+}$, which is acting as oxidizing agent. The electrons on the surface of the $\mathrm{TiO}_{2}$-particles can diffuse away and become solvated:

$$
\mathrm{e}^{-}+\mathrm{nH}_{2} \mathrm{O} \rightarrow \mathrm{e}_{\mathrm{aq}}^{-} \text {(solvated electrons). }
$$

The solvated electrons $\left(\mathrm{e}_{\mathrm{aq}}^{-}\right)$as well as $\mathrm{e}^{-}$on the semiconductor-surface are able to react with $\mathrm{H}^{+}$in acid 
H.-R. Park et al. · Photoinduced CO-Reduction in Aqueous Suspension of n- $\mathrm{TiO}_{2}$

aqueous solution, resulting in $\mathrm{H}$-atoms:

$\left(\mathrm{e}^{-} \cdot \mathrm{TiO}_{2}^{+}\right)+\mathrm{H}_{\mathrm{aq}}^{+} \rightarrow \mathrm{H}+\mathrm{TiO}_{2}^{+}$,

$\mathrm{e}_{\mathrm{aq}}^{-}+\mathrm{H}_{\mathrm{aq}}^{+} \rightarrow \mathrm{H}\left(k=2.3 \times 10^{10} \mathrm{M}^{-1} \mathrm{~s}^{-1}[15]\right)$.

Both types of reducing species, electrons as well as $\mathrm{H}$-atoms, can react with $\mathrm{CO}$ producing $\mathrm{CHO}-$ transients:

$\left(\mathrm{e}^{-} \cdot \mathrm{TiO}_{2}^{+}\right)+\mathrm{CO} \rightarrow \mathrm{CO}^{-}+\mathrm{TiO}_{2}^{+}$,

$\mathrm{e}_{\mathrm{aq}}^{-}+\mathrm{CO} \rightarrow \mathrm{CO}^{-}\left(k=1 \times 10^{9} \mathrm{M}^{-1} \mathrm{~s}^{-1}[16]\right)$,

$\mathrm{H}_{\mathrm{aq}}^{+}+\mathrm{CO}^{-} \rightarrow \mathrm{CHO}$,

$\mathrm{H}+\mathrm{CO} \rightarrow \mathrm{CHO}\left(k=3.8 \times 10^{8} \mathrm{M}^{-1} \mathrm{~s}^{-1}[17]\right)$,

The reactions (3) and (5) as well as (4) and (6) are competing processes.

The CHO-radicals can lead to the formation of formaldehyde or to some extent glyoxal.

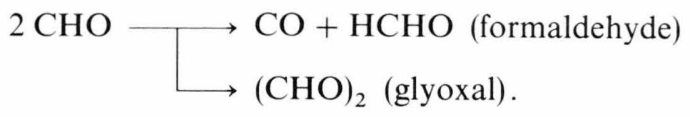

At low CO-concentrations the primary species, $\mathrm{e}_{\mathrm{aq}}^{-}$ and $\mathrm{H}$, can combine with each other producing hydrogen:

$\mathrm{e}_{\mathrm{aq}}^{-}+\mathrm{e}_{\mathrm{aq}}^{-} \rightarrow \mathrm{H}_{2}+2 \mathrm{OH}^{-}$

$$
\left(k=5 \times 10^{9} \mathrm{M}^{-1} \mathrm{~s}^{-1}[18]\right),
$$

$\mathrm{H}+\mathrm{H} \rightarrow \mathrm{H}_{2} \quad\left(k=1 \times 10^{10} \mathrm{M}^{-1} \mathrm{~s}^{-1}[19]\right)$,

$\mathrm{e}_{\mathrm{aq}}^{-}+\mathrm{H} \rightarrow \mathrm{H}_{2}+\mathrm{OH}^{-}$

$$
\left(k=2.5 \times 10^{10} \mathrm{M}^{-1} \mathrm{~s}^{-1}[20]\right) .
$$

The yield of hydrogen was not studied in this work.

On the other hand, the positive holes $\left(\mathrm{p}^{+}\right.$resp. $\mathrm{TiO}_{2}^{+}$) are able to oxidize water or to produce $\mathrm{OH}$ radicals depending upon the $\mathrm{pH}$ of the solution:

$$
\begin{aligned}
& \mathrm{TiO}_{2}^{+}+\mathrm{H}_{2} \mathrm{O} \rightarrow \mathrm{TiO}_{2}+\mathrm{O}_{2}+\mathrm{H}^{+}, \\
& \mathrm{TiO}_{2}^{+}+\mathrm{OH}^{-} \rightarrow \mathrm{TiO}_{2}+\mathrm{OH} .
\end{aligned}
$$

[1] H.-R. Park and N. Getoff, Z. Naturforsch. 43a, 430 (1988).

[2] H.-R. Park and N. Getoff, J. Photochem. Photob., A: Chemistry 43, 155 (1988).

[3] W. Vonach and N. Getoff, Z. Naturforsch. 36a, 876 (1981).

[4] M. Grätzel (ed.), Energy Resources Through Photochemistry and Catalysis, Academic Press, New York 1983.
The $\mathrm{OH}$-radicals are reacting with $\mathrm{CO}$ forming $\dot{\mathrm{COOH}}$ radicals in competition with $\mathrm{OH}$ recombination:

$\mathrm{CO}+\mathrm{OH} \rightarrow \mathrm{COOH}\left(k=8.3 \times 10^{8} \mathrm{M}^{-1} \mathrm{~s}^{-1}\right.$ [21] $)$,

$\begin{aligned} \mathrm{COOH}+\mathrm{COOH} \longrightarrow & \mathrm{HCOOH}+\mathrm{CO}_{2} \quad \text { (16a) } \\ \longrightarrow & \mathrm{H}_{2} \mathrm{C}_{2} \mathrm{O}_{4} \text { (oxalic acid), }\end{aligned}$

$\mathrm{COOH} \rightleftharpoons \mathrm{CO}_{2}^{-}+\mathrm{H}^{+}(\mathrm{pK}=1.4[22])$,

$\mathrm{OH}+\mathrm{OH} \rightarrow \mathrm{H}_{2} \mathrm{O}_{2}\left(k=6 \times 10^{9} \mathrm{M}^{-1} \mathrm{~s}^{-1}[19]\right)$.

Since the $\mathrm{OH}$-species are mainly adsorbed on the semiconductor surface they seem to recombine (reaction (18)), rather then to form acids (reaction (15) and (16)), because only traces of formic acid could be detected.

The appearance of $\mathrm{H}_{2} \mathrm{O}_{2}$ explains at least partly the decomposition of formaldehyde at higher uv-doses (see Fig. 1 and Figure 4A).

The lack of formaldehyde formation in alkaline solution could be explained by the formation of O-atoms, which decompose the eventually formed organic compounds:

$\mathrm{OH} \rightleftharpoons \mathrm{O}^{-}+\mathrm{H}^{+}(\mathrm{pK}=11.8[23])$,

$\left(\mathrm{e}^{-} \cdot \mathrm{TiO}_{2}^{+}\right)+\mathrm{O}^{-} \rightarrow \mathrm{e}_{\mathrm{aq}}^{-}+\mathrm{TiO}_{2}+\mathrm{O}^{\circ}$.

It is worth to be mentioned that using $\mathrm{n}-\mathrm{TiO}_{2}$ powder in the presence of $1 \times 10^{-3} \mathrm{M} \mathrm{CO}$ in aqueous acid solution ( $\mathrm{pH}=2$; see Fig. 1) the obtained formaldehyde yield at $\lambda=254 \mathrm{~nm}$ is several orders of magnitude higher (1.6 M HCHO for $8 \mathrm{hr}$ irradiation, based on $Q_{\mathrm{i}}=4 \times 10^{-4}$ ) than the previously reported one [8] of $0.32 \times 10^{-6} \mathrm{M} \mathrm{HCHO}$ after $8 \mathrm{hr}$ irradiation time. The aldehyde yield obtained in the present work under the influence of the HPK $125 \mathrm{~W}$-lamp for the same irradiation time amounts to $1.6 \times 10^{-4} \mathrm{M} \mathrm{HCHO}$ (see Fig. 4, curve A).

\section{Acknowledgement}

One of us (N.G.) appreciates very much the financial support by the Jubiläumsfonds der Österreichischen Nationalbank.

[5] N. Getoff, unpublished results (1982).

[6] N. Getoff, S. Solar, and W. Solar, in: Hydrogen Energy Progress VI, Vol. 2, p. 512 (T. N. Veziroglu, N. Getoff, and P.Weinzierl, eds.). Pergamon Press, Oxford 1986.

[7] R. M. Quint and N. Getoff, Int. J. Hydrogen Energy 13, 269 (1988).

[8] S. Yamamura, H. Kojiama, and W. Kawai, J. Electroanal. Chem. 186, 309 (1985). 
[9] J. Moser and M. Grätzel, Helv. Chim. Acta 65, 1436 (1982).

[10] E. B. Sandoll, Colorimetric Determination of Traces of Metal. Intersci. Pub. Comp., New York 1959.

[11] M. Neumann-Spallart, and N. Getoff, Monatsh. Chemie 106, 1359 (1975).

[12] T. Nasch, Biochem. J. 55, 418 (1958).

[13] N. Getoff, K.-J. Hartig, G. Kittel, G. A. Peschek, and S. Solar, Wasserstoff als Energieträger, Springer-Verlag, Wien 1977.

[14] N. Getoff, in: Solar Energy 85, Proceed. of Summer School held in Igls, Austria, ESA SP-240 (1985).

[15] L. M. Dorfman and I. A. Taub, J. Amer. Chem. Soc. 85, $2370(1963)$

[16] E. J. Hart, J. K. Thomas, and S. Gordon, Radiat. Res. Suppl. 4, 74 (1964).
[17] D. Seitner and N. Getoff, Monatsh. Chem. 100, 1868 (1969).

[18] S. Gordon, E. J. Hart, M. S. Matheson, J. Rabani, and J. K. Thomas, J. Amer. Chem. Soc. 85, 1375 (1973).

[19] J. K. Thomas, J. Phys. Chem. 67, 2593 (1963).

[20] M. S. Matheson and J. Rabani, J. Phys. Chem. 69, 1324 (1965).

[21] Y. Raef and A. J. Swallow, Trans. Faraday Soc. 59, 1631 (1963).

[22] G. V. Buxton and R. M. Sellers, J.C.S., Faraday Trans. 69, 555 (1973).

[23] J. W. T. Spinks and R. J. Woods, An Introduction to Radiation Chemistry, John Wiley \& Sons, New York 1976. 